\title{
Traditional Spices in Japanese Modern Food
}

\section{Sriwahyu Istana Trahutami*}

Japanese Language and Culture Study Program, Faculty of Humanities, Diponegoro University, J1 Prof Soedarto (Diponegoro University), Semarang, Central Java, Indonesia.

\begin{abstract}
This article describes the traditional seasoning (choumiryou) used in modern Japanese cuisine. The purpose of this study was to determine the types and ways of making traditional spices in Japanese cuisine, and how to use them to give color and flavor to the dishes. This research is a literature study. The author documents data about shokubunka or Japanese eating culture and traditional spices from various literatures. Through qualitative descriptive methods it is known that modern Japanese cuisine still retains traditional spices, especially miso, shoyu and dashi. The main ingredients of choumiyou are rice, soybeans, and fish. The manufacturing process by means of fermentation that takes a long time for months is the key to the deliciousness of seasoning while adding natural nutrition.
\end{abstract}

Keywords: Japanese food; choumiryo; traditional spices

\section{Introduction}

Japanese population has the highest life expectancy in the world. The average age of men is 78 years, while women reach the age of 85 years. Statistics of the Ministry of Population in Japan said that the number of people over the age of 100 years increased and became 20.561 people in 2003. Whereas it reached 20.000 in the previous year [1]. This showed that the life expectancy in Japan is increasing every year.

One of the reasons why life expectancy in Japan is higher than the other countries is the food factors. Basically, traditional food is a recipe for longevity. It is undeniable that the food eaten for decades is an important factor which becomes the longevity secret. Japanese traditional food is a tradition of ancestral heritage from generation to generation. It is good for health, containing good nutrition that slows the cell aging [2]. So, the aging process of the Japanese is slower than the other citizen in the world.

Food can not be separated from spices. The spices will give a delicious taste and give color to the food. Washoku or Japanese food that has been recognized by UNESCO as an intangible cultural heritage has special spices produced from nature. There are 5 spices used in Japanese food. These herbs are mentioned in order based on the sequence of Japanese

\footnotetext{
${ }^{*}$ Corresponding author : sriwahyuistanatrahut $@$,lecturer.undip.ac.id
}

Deleted:

Deleted: . 
Hiragana namely sa, shi, su, se, and so. Sa is sato or sugar, shi is shio or salt, su is cooking vinegar, se is seuyu which is the original word of shoyu or soy sauce, and so is miso. Spices or Choumiryo sashisuseso is a type of spices that is commonly used in Japanese food as well as showing the order of using these spices into cooking [4].

Japanese food used a lot of spices. The making technique of traditional spices relies on Japanese climate and geographical conditions. Spices have a long historical tradition and are still preserved how the way to make it in a traditional way.

Many studies on Japanese spices had been conducted [1] in their journal article discussing the eating habits of Japanese and Chinese immigrants [6]. This article discussed how traditional herbs are used in Japanese (washoku) food today. While the purpose of this article was to fully describe what are the types of traditional choumiryou in Japanese food and the techniques for making these basic spices. In addition, an overview of how Japanese home cooking can be obtained through a description of basic spices that focus on miso, shoyu, and dashi_ [3].

\section{Method}

This research used a descriptive method through a qualitative approach. The data collecting method was the library method. The technique used was the documentation technique. As an effort in collecting data, the writer documented the written sources in the form of journal articles and books about shokubunka (food culture), especially those related to washoku and traditional herbs [4]. While observations were made through the use of choumiryou phenomenon in Japanese food which was analyzed based on recipes.

The next stage was the analysis phase. The data were analyzed using a qualitative descriptive method. The description was done by describing facts based on non-numeric data to answer the problem in this study. The method used in this research was a descriptive qualitative research method that was descriptive, using data references and supported by existing theories [5].

\section{Results and Discussion}

\subsection{Basic Japanese Food and Nutrient Content}

Basic Japanese food is what is called ichi ju san sai which is 3 kinds of side food that are eaten with miso soup and rice. These 3 side food are the main side food and 2 kinds of side food. Ichi ju san sai was developed by the Japanese military in the Muromachi Era of the 14 th century until the 16th century which is still being used as a standard until now. The main side food is high protein instead of vegetables. Fish are commonly used as the main ingredient either eaten raw or cooked through boiling, grilling, or another. One of the complementary side food is usually boiled and seasoned, for example, potatoes, carrots, turnips, seaweed or konbu. Other complementary side food might be natto (fermented soybeans), tofu, cooked beans, boiled vegetables soaked in broth and seasoned with soy sauce or sweet vinegar such as various pickles. The most common are pickled apricots or umeboshi [3].

Japanese people really like the food ingredients obtained in that season, so the freshness and delicious taste is maintained. The use of fish and vegetables are harvested in that season. The nutrient content is also very considered in the diet of ichi ju san sai [3]. Rice contains lechitin which can increase the work of the brain, oligosaccharide which refreshes the intestine and gamma amino butyric acid which can stabilize blood pressure. Soybeans and preparations including miso paste which is a seasoning soup, tofu, boiled soybeans and

\section{Deleted:}

Deleted: ,

Deleted: .

Deleted:

Deleted: 
natto contain $35 \%$ protein similar to meat. It also contains polyphenols and isoflavones which are beneficial for female hormones, prevent bone fragility and increase bone mass, soybeans also can slow cell aging [3]. Fermented soybeans contain high amino acids which increase longevity over the past centuries. Also, fish is containing DHA to increase intelligence and contain EPA to improve blood circulation. Vegetables and tofu and seaweed are all sources of vitamins, minerals, fiber, and antioxidants that are needed by the body. In addition, the Japanese habit of drinking green tea in a basic dietary pattern was also very beneficial for living a long life. Catechin content found in green tea can prevent cell oxidation, cancer and various diseases due to modern lifestyle patterns [1]. Moreover, the use of traditional herbs as cooking ingredients also gives a delicious taste while adding nutrient content to the ingredients. This is because most of the spices in Japanese food are also made from high nutritional ingredients, such as soybeans and fish products which are processed through the process of fermentation, drying, boiling and other processes that all require several months to get an optimal taste [3].

\subsection{Spices and Its Making Process}

The types of traditional spices that would be presented in this article are Japanese shoyu or soy sauce, miso which is the basic spice for making soup, konbu or seaweed, dashi or broth which is the key to Japanese food [3].

\section{A. Miso}

Miso is a seasoning pasta made of soy, which is obligated spices for Japanese soup, such as shoyu. Every home-cooked food in Japan used miso or misoshiru soup as the daily menu and the main complementary menu that always served for dining. This soup was made by the ready-made broth added with tofu, wakame, or other ingredients, then miso pasta itself. Miso has the function of removing the smell of fish and meat, as well as causing a good taste in cooking ingredients. Also, it always uses for cooking spices that are boiled. It is made of steamed, crushed and salted soybeans then mixed with koji mushrooms as fermentation. The Koji mushrooms mixed in soybeans, rice, wheat, or other grains, then left for months or even a year for the fermentation process. This making miso technique was originated in China which was known more than 1300 years ago [6]. There are three main types of miso that exist in Japan, they are:

a. Miso kome (a mixture of koji mushrooms and rice)

b. Miso mugi (a mixture of koji mushrooms and mugi wheat)

c. Miso mame (a mixture of koji mushrooms and beans)

Miso kome is the most widely used miso and has a slightly different taste and color in each region. People who live in cold regions tend to prefer darker-colored miso kome with more salt, while people who live in southern Japan with warm temperatures tend to consume miso with a lighter color and taste [3].

\section{B. Shoyu}

Shoyu or soy sauce is also spices that should be contained in almost every food. Soy sauce is made from soy. Soybeans, wheat and salt are put in the water. Then, it is added with water and koji mushrooms and made until porridge or moromi looks like, and it will be left 
for a few months. After the fermentation process is finished, the porridge is squeezed. The resulting water is boiled to remove bacteria and then it is called shoyu. There are three types of shoyu on the market, they are:

a. Koi kuchi is soy sauce with strong color and strong taste. This type is the most popular type.

b. Usu kuchi is a soy sauce with a light color and lighter taste. It does not change the food taste.

c. Tamari is soy sauce with a higher soybean content and less salt content than the other types of shoyu.

\section{Dashi}

Dashi or broth is the main key to Japanese food. Dashi is made from the broth of dried bonito fish, dried small fish, konbu seaweed, dried shiitake mushrooms or its kind. This broth is cooked for a long time to bring out the delicious taste. The main basic broths are dashi made from konbu seaweed and dashi made from dried bonito.

a. Konbu Dashi

Konbu or seaweed already has a delicious original taste. After the seaweed has been harvested, it will be dried by relying on the sunlight for the drying process. This process takes two to three days. The ways to make konbu broth are done by cutting the konbu to the desired size, putting it in a pan filled with water, and heating until it boiled. Konbu is removed after it is boiled. The broth produced by konbu is a clear broth, it tastes light so it is suitable for cooking suimono soup or other recipes that require the clear broth.

\section{b. Katsuo Dashi}

Katsuo broth comes from dried bonito or katsuo bushi or skipjack fish. This dried fish is called the hardest food in the world because it resembles wood. Dried bonito fish is shaved to make broth. The next steps are to put the shavings of the fish in water that has boiled or almost boiled, turn off the heat, let stand a moment then lift. The broth from the first bonito stew is called ichi ban dashi (the number one broth). Then, the fish shavings in the first broth can be reused to produce ni ban dashi (the number two broth).

Katsuo bushi is derived from bonito which is cut into large pieces to take the meat after washing. Furthermore, the fish pieces are boiled at temperature for about 90 degrees to avoid the fish cracked. After the boiling process, the fish and the bones are removed from the water, then it cut to a smaller size. The next piece of fish is smoked with a small wood fire, cooled to room temperature and it is repeated several times. The product produced is arabushi. Arabushi is shaved and wrapped, then it can be consumed. Nevertheless, it still needs a few more steps to produce the original broth. Arabushi must be dried again, the top and the outside of Arabushi shaved can produce a hadakabushi. The dried hadaka bushi will be stored in a temperature and humidity-controlled room until aspergillus fungus grows on its surface. The next process is dried it again but the fungus is removed, and it should be stored again in the curing chamber until 4 times repetition to produce the original honbushi product. The fungus will naturally and slowly release water to the fish, so that the fish becomes dry and hard, also it adds to the amino acid content as well as adding a delicious taste to the final cooking [3]. 
Nowadays, people will no longer be occupied to make the basic spices of Japanese food which are very long in its making process. It is because so many instant spices products had been produced. However, there are still many well-known companies that preserve the producing spices traditionally to make an authentic umami (delicacy) [6].

Besides the basic spices described above, there are still a few more traditional choumiryo that are often used in Japanese food, such as sake wine, vinegar and mirin (sweet sake). Mirin has a sweet taste and it is usually used to provide a balance of salty shoyu, so that a savory taste is obtained. It is also used to reduce the acidity in vinegar. In Japanese food, spices with sharp taste are avoided to maintain the original flavor of the processed ingredients. Other spices used are flavorful or soft-scented, such as kinome (aromatic springs) from sansho trees, yuzu (citrun), wasabi (Japanese horserafood), ginger, myouga, and crushed dried sansho seeds [3].

\section{Conclusion}

One of the reasons why Japanese people live longer is because of their diet. Since a long time ago, their ancestors had traditionally consumed nutritious and balanced food. In Buddhist teachings, Japanese people have never consumed red meat since long time ago, so their main consumption is rice, various types of fish, and vegetables as well as tubers and beans. Japanese people also have a habit of eating fish, vegetables and fruit harvested in that season, for example, bamboo sprout in spring, oranges in winter, sanma fish and matsutake mushrooms in autumn [3]. According to Japanese people, the harvest of vegetables and fish harvested at that time is the best results with the best nutrient content compared to the other seasons [6].

Not only the basic ingredients which have good quality, Japanese traditional spices usually consist of spices that are produced from fish, soybeans, and fermented rice. It takes a long time process to get to the best flavor from the spices. The fermentation process of soybean produces miso products and various types of shoyu. The rice fermentation produces vinegar or $s u$ and cooking wine (sake used for seasoning), and mirin (sweet wine). The complicated and long process of bonito fish produces katsuo bushi which is the basic spices for dashi that used for various food. Also, konbu seaweed is processed to become the basic spices of konbu broth. Japanese food usually maintains the original taste of its original ingredients and some are even eaten raw like sushi and sashimi. Spices such as soy sauce and miso are almost used in all food, it can be a seasoning sauce or used as the basic spices in soups or stewed food [3].

\section{References}

1. Photo, Margherita. Food Law Under The Rising Sun. Berlin: Lexxion (2010)

2. Danandjaja, James. Folklore Jepang: Dilihat dari Kacamata Indonesia. Jakarta:Pustaka Utama Grafiti (1997)

3. Junko TSUDZUKI and Keiko NAKASHIMA, 2001, Influence of Using "Sonota no Choumiryo" on the Amount of Salt lntake, 椙山女学園大学研究論集 第32号（自然科学篇）

4. Koentjaraningrat, Beberapa Pokok Antropologi Sosial. Jakarta: Dian Rakyat. (1992)

5. Rahman, Fadli..Jejak Rasa Nusantara.Jakarta: PT. Gramedia Utama. (2016)

6. Sugimoto, Yoshio. An Introduction to Japanese Society. Melbourne: Cambridge. (2014) 